\title{
Legitimacy, Hate Speech, and Viewpoint Discrimination
}

\author{
Gideon Elford \\ New College, University of Oxford, Oxford, United Kingdom \\ gideon.elford@new.ox.ac.uk
}

\begin{abstract}
One of the most powerful arguments against state regulation of expression has, in recent years, been presented in a reinvigorated and developed form. The argument in question maintains that state regulation of expression undercuts the legitimacy of the law because it involves the suppression of a source of democratic contestation. The paper distinguishes between three importantly different versions of this legitimacy argument that existing work fails to clearly separate. Doing so is important because different forms of the legitimacy argument are supported by different considerations, vulnerable to different objections, and have different implications. Further, the paper levels two serious objections to legitimacy arguments against hate speech regulation. Firstly, it offers a consolidated defence of an extant rejoinder to the legitimacy argument, based on the claim that some person's speech can 'silence' the expression of others. Secondly, the paper challenges the claim that the regulation of hate speech is necessarily viewpoint discriminatory.
\end{abstract}

\section{Keywords}

freedom of expression - hate speech - legitimacy - viewpoint discrimination

Within the voluminous work that defends freedom of expression against the threat of state regulation, the argument that such regulation threatens the legitimacy of the laws of the state is among the most powerful. Broadly speaking, the argument maintains that state regulation of expression has the effect of undercutting the legitimacy of the laws of the state because it involves the suppression of a source of democratic contestation. The argument in question 
has considerable force for more than one reason. Democracy is not only widely accepted as an important value, it is also commonly considered an important prerequisite for legitimacy by parties to the debate over whether, and in what cases, expression can permissibly be restricted. This legitimacy argument finds its roots in the work of Alexander Meiklejohn ${ }^{1}$ but it has been recently reinvigorated in more developed and thoroughgoing versions of the position by a growing number of scholars, including Ronald Dworkin. ${ }^{2}$ Moreover, contemporary ways of framing the legitimacy argument make it appear to be a particularly potent dialectical weapon in the contestation over expression regulation. In a move of some ingenuity, defenders of the legitimacy argument suggest that speech regulation deleteriously affects the very laws designed to protect the interests of those who are typically the targets of the regulated speech. With no small irony, it is anti-discrimination laws protective of the rights of members of minority groups that are precisely the laws whose legitimacy is undermined by regulation that seeks to shield such minorities from the would-be harms of others' speech. Nor is this a coincidence. It is because such minorities are the typical targets of hate speech that the regulation of hate speech tends to eliminate the very speech that is putatively important for protective anti-discrimination laws to survive the right kind of democratic contestation.

The paper offers a threefold contribution to the question of whether the legitimacy of the law is undercut by the regulation of expression such as hate speech. Firstly, it offers an important clarification by way of distinguishing between three different versions of the legitimacy argument that existing work has failed to separate. Distinguishing between those versions is important, I argue, because the considerations which respectively support different versions are themselves importantly different from one another. Secondly, the paper offers a consolidated defense of a rejoinder to the legitimacy argument which remains hitherto underdeveloped. The rejoinder in question appeals to

$1 \quad$ Alexander Meiklejohn, Free Speech and Its Relation to Self-Government (New York: Harper Brothers, 1948).

2 Ronald Dworkin "Foreword" in Extreme Speech and Democracy, Hare and Weinstein (eds.) (Oxford University Press, 2009). See also, James Weinstein, "Participatory Democracy and Free Speech," VA. L. REV. 97 (2011); James, Weinstein, "Hate Speech Bans, Democracy, and Political Legitimacy," Constitutional Commentary Vol. 32 (2017), pp. 527-583; Eric Heinze, "Taking Legitimacy Seriously: A Return to Deontology," Constitutional Commentary. Vol. 32 (2017), pp. 631-65o; Eric Heinze, Hate Speech and Democratic Citizenship (Oxford University Press, 2016); Robert Post, "The Constitutional Status of Commercial Speech," UCLA L. REV. 48 (2000); Corey Brettschneider, When the State Speaks, What Should It Say? (Princeton University Press, 2012); C. Edwin Baker, "Autonomy and Free Speech," Constitutional Commentary Vol. 27 (2011), pp. 251-282. 
the idea that some persons' speech can meaningfully 'silence' the speech of others. If this is the case, the argument runs, then legitimacy can in fact be served by the regulation of speech that has this silencing effect. Defenders of the legitimacy argument have tended to reject this response, often on the basis of skepticism as to the available evidence for bone fide damage to freedom of expression for which state regulation is a putatively important remedy. The paper supports this silencing rejoinder by showing that existing accounts of the damage inflicted on individuals' freedom of expression by sources within civil society have failed to address a crucial dynamic by which individuals' freedom of expression can be restricted. Once we appreciate the full range of the ways in which individuals' freedom to express can be restricted, it becomes clear that the legitimacy argument can, in principle, militate in favor of regulation. Thirdly, the paper challenges the central contention of the legitimacy argument that the regulation of hate speech is viewpoint discriminatory. In doing so, the paper shows that a crucially important part of the case against the regulation of expression in fact fails to rule out the regulation of many of the kinds of speech it purports to protect.

\section{The Legitimacy Argument(s) against the Regulation of Expression}

The legitimacy argument is like a great many in political philosophy; its essentials are straightforward to grasp, but its depths reveal intricacies that are fiendishly subtle and complex. One of the important prerequisites for meaningful citizen engagement in democratic politics is the enjoyment of a domain of free expression. Free expression is an essential part of the process of holding governments to account and for citizens to form their own views with respect to which governments and laws may or may not be worthy of endorsement. Without the possibility of expressive dissent, citizens are deprived of an important resource by which to voice and, importantly, to hear and reflect on views that are critical of different legislative proposals. For the most compelling visions of the value of democracy, the freedom to participate in debate, judgment, and construction of the law must also be enjoyed equally by all citizens. Furthermore, it is often thought that governments instituted through such a democratic process enjoy a dimension of legitimacy that governments without such credentials lack. Under this picture of the place of freedom of expression in a democracy, the legitimacy argument against the restriction of freedom of expression is both clear and plausible. To place limits on what citizens can express to one another would be to corrode the very foundations of democracy on which the legitimacy of the law is grounded. In the newly innovated form 
of the argument in contemporary work, the claim is not simply that the democratic character of the state is risked or jeopardized but that, because the connection between freedom of expression and democracy is so vital, to restrict freedom of expression is to inflict constitutive damage on democracy and, in doing so, to deprive the law of legitimacy. As Dworkin puts it, "[f] air democracy requires ... that each citizen have not just a vote but a voice: a majority decision is not fair unless everyone has had a fair opportunity to express his or her attitudes or opinions or tastes or presuppositions or prejudices or ideas, not just in the hopes of influencing others (though that hope is crucially important), but also just to confirm his or her standing as a responsible agent in, rather than passive victim of, collective action. The majority has no right to impose its will on someone who is forbidden to raise a voice in protest or argument or objection before the decision is taken."

The tight connection between freedom of expression and legitimacy, and the dependence of the latter on the protection of the former, has been echoed by several others in recent work. James Weinstein writes that, "[i]f an individual is excluded from participating in public discourse ... any decision taken as a result of that discussion would, as to such an excluded citizen, lack legit-

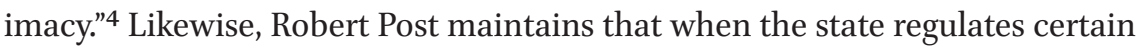
forms of expression, "[i]t prevents persons from participating in a process of public-opinion formation in ways that would make the law responsive to them, With respect to such persons, the state has pro tanto ceased to be legitimated. ${ }^{5}$ Eric Heinze draws a similar connection between legitimacy and free expression on the grounds that free expression is a "distinctively democratic interest" 6 and an "essential attribute of democratic citizenship,"7 and, for this reason, he denies that "public discourse can legitimately be regulated." ${ }^{8}$

As is only to be expected with any argument invoking a contested and normatively laden term such as 'legitimacy, at least part of the existing debate has revolved around the clarification and refinement of the term itself and a specification of what kind of state 'legitimacy' damage is entailed by the regulation of speech. There is a question of whether legitimacy is intended in a normative or a descriptive sense. If normative, it could refer to the justification of state

3 Dworkin - Foreword VII.

4 Weinstein - Participatory Democracy and Free Speech, p. 498.

5 "Interview with Robert Post", in The Content and Context of Hate Speech: Rethinking Regulation and Responses Michael Herz and Peter Molnar (eds.) (Cambridge University Press, 2012), pp. 11-37, at p. 25.

6 Heinze - Hate Speech and Democratic Legitimacy, p. 5 .

7 Ibid., p. 4.

8 Ibid., p. 4 . 
coercion, or the obligations citizens have to act in accordance with what the state commands as law, or both. ${ }^{9}$ At issue is also whether the would-be legitimacy damage inflicted by expression regulation is incurred to specific laws or in a more systemic sense to the legitimacy of the state as a whole. ${ }^{10}$ It's also worth noting that the extent to which either justification for state coercion or political obligation are undermined by the regulation of expression is itself a matter that admits of degree. That is, legitimacy might be undercut merely to some extent, or there might be a more wholesale destruction. ${ }^{11}$ Further to this, critics and advocates of the legitimacy argument also sometimes respectively differ over whether legitimacy is best understood in relation to what can be justified to reasonable citizens according to a contractualist methodology, ${ }^{12}$ or whether it is a specifically democratic notion relating to what is justified to citizens through democratic procedures. ${ }^{13}$

Such further complexities aside, the legitimacy argument embodies a potent thought. State actions require, for their legitimacy, vindication by democratic participation for which freedom of expression is crucially important. This general legitimacy case against the regulation of expression should in fact be divided into three closely related but importantly distinct claims. The first form of the argument emphasizes the democratic importance of a free and undistorted popular debate as playing an important educative, informing role in equipping the democratic citizenry with the knowledge and understanding to make an informed and relevantly autonomous choice in the selection of the laws that apply to them. ${ }^{14}$ From this perspective, it is as important for citizens to be able to hear and receive a range of views and perspectives as it is for them to be given the opportunity to themselves contribute to and influence the debate. Legitimacy is thereby undercut when the debate is distorted, and the domain of democratic contestation is in some way corrupted or constrained by state interjection that limits what can be said or heard. Thus understood, freedom of expression is an instrument for securing a civic debate fertile enough to sustain an informed and autonomous democratic will. It is in this

9 Arthur Ripstein, "Authority and Coercion," Philosophy and Public Affairs 32 (2004), pp. 2-35.

10 Weinstein - Hate Speech Bans, p. 535 .

11 Jeremy Waldron, "Hate Speech and Political Legitimacy," in The Content and Context of Hate Speech: Rethinking Regulation and Responses, Michael Herz and Péter Molnár, eds. (Cambridge University Press, 2012) at pp. 332-334.

12 Alexander Brown, Hate Speech Law: A Philosophical Examination (Routledge, 2015), at p. 208.

13 For contrasting views compare Alexander Brown, "Laws, Legitimacy, and Precaution," Constitutional Commentary Vol. 32 (2017), pp. 599-617, and Weinstein - Viewpoint Discrimination, p. 760 .

See Meiklejohn - Free Speech and Self-Government. 
vein that problems associated with misinformation and so-called fake news have been seen as specifically democratic problems.

On a second form of the argument, the connection between free expression and democracy is still tighter. Here it is argued that free expression is not just crucial for but constitutive of the democratic process. ${ }^{15}$ When a person is deprived of a voice they are in effect dispossessed of (at least part of) their input in the process by which law is created and, as a result, the law isn't properly democratic, at least with respect to the person whose speech is restricted. Weinstein emphasizes this by suggesting that, "a crucial purpose of free speech [is] ... the opportunity for each individual to participate as an equal in the public conversation about society's collective decision."16 This second version of the legitimacy argument points towards a further, third incarnation under which the state's dispossession of a person's voice constitutes a violation of a person's right to an equal voice in the democratic process, and for that reason itself oversteps the bounds of legitimate state action. Pre-empting a person's expressive contribution by way of a judgment about the moral or factual credentials of that person's views violates what Dworkin refers to as the "right of ethical independence."17

I won't extensively discuss the first form, though I think that it has the longest pedigree of the three and there are indeed worthwhile questions to be explored as to which influences have a 'distorting' and corrupting impact on the appropriately informed and autonomous development of citizens' democratic participation..$^{18}$ Rather, I shall focus on the second and third versions of the argument which have yet to be clearly distinguished from one another in the emergent literature. Distinguishing them is important given that they respectively appear to support two quite different conclusions concerning the locus of legitimacy damage inflicted by the regulation of expression. The second argument supports the claim that the regulation of expression undercuts the legitimacy of certain further 'downstream' laws. In this way the legitimacy damage incurred by regulation expression is consequential on the regulation

15 Dworkin - Foreword v.

16 Weinstein - Hate Speech Bans, p. $5^{28}$.

17 Dworkin - Reply, p. 342.

18 One way of broadly distinguishing the second and third versions of the argument from this first form is to note that the first argument emphasizes the freedom and autonomy of citizens to arrive at the views they bring to, and develop from, democratic contestation, whereas the second and third forms emphasize the inequality implicated in restricting certain persons' expression. For an account embracing the first form see Geoffrey R. Stone, "Content-Neutral Restrictions," U. Chi. L. Rev 54 (1987). For a response see Jeremy Waldron, "Dignity and Defamation: The Visibility of Hate," Harv. L. Rev. 123 (2010). 
and pertains to further actions the state might take rather than the regulation itself. In contrast, the third argument supports the claim that the regulation of expression is itself illegitimate, in virtue of the fact that the state's authority does not allow for the certain kinds of regulation of expression. On this third view both the law regulating the expression and the 'downstream' state action related to that regulation lack legitimacy.

Before I elaborate on the strongest response to the legitimacy arguments, it is worth pausing to emphasize that the advocates of the legitimacy arguments do not argue that any and all regulation of expression undermines legitimacy. None would deny, for instance, that certain so-called 'time, place, and manner' restrictions leave democratic legitimacy untouched. Rather, as I will later explore, the legitimacy grounds marshalled to protect free expression specifically pertain to the protection of expression against certain justifications for regulation. More specifically, they oppose supressing speech based on the character of the viewpoint that the speech in question expresses. For this reason, the legitimacy argument has most frequently been trained against the regulation of hate speech and related forms of speech deemed in some way noxious or out of place in civilized society. ${ }^{19}$ As Weinstein puts it, "hate speech bans are inherently viewpoint discriminatory. Britain's hate speech law, for instance, restricts only speech that intends to "stir up racial hatred" but not expression promoting racial tolerance."20 To make the legitimacy case against the regulation of hate speech still stronger, because the regulation of hate speech targets specific viewpoints, it tends to inflict particular damage on the very laws that are otherwise designed to protect the people vulnerable to hate and discrimination. Dworkin aptly captures the thrust of this view when he explains that although laws protecting "women and homosexuals and members of minority groups from specific and damaging consequences of sexism, intolerance, and racism" are no doubt important, "we must not try to intervene further upstream, by forbidding any expression of the attitudes of prejudices that we think nourish such unfairness or inequality, because if we intervene too soon in the process through which collective opinion is formed, we spoil the only democratic justification we have for insisting everyone obey those laws."21

In what follows I present two serious objections to the legitimacy argument that correspond to the second and third versions of the argument enumerated

19 Though the application of the argument is far from limited to the permissibility of hate speech regulation, as, for instance, Weinstein is at pains to make clear.

20 Weinstein - Hate Speech Bans, p. 545 .

21 Dworkin Foreword viII. 
above. In response to the argument of the second form - that viewpoint discriminatory speech regulation can unfairly dispossess some persons of their democratic say - I argue that because civil society can, in various ways, itself stifle free expression, the legitimacy argument in fact counsels in favor of regulation of expression, at least in principle, insofar as it is necessary to preserve substantial democratic expressive participation for some citizens. Whilst this objection to the legitimacy argument has previously been put forward, the strongest case for the objection has yet to be made. This is because present incarnations of the challenge fail to explore a crucial dynamic whereby persons can have their democratic say meaningfully frustrated. Significantly, I will argue that similar mechanisms by which the state restricts freedom of expression, and hence, if the argument is correct, damage legitimacy, are also ones by which broader social phenomena can limit expression. My response to the argument of the third form is predicated on interrogating the notion that the regulation of hate speech is viewpoint discriminatory. I argue that insofar as hate speech regulation targets the consequences of speech that are contingently connected with the substance of what is expressed then it is viewpoint discriminatory in only an indirect sense. If so, this significantly weakens the claim that a person's right to an equal voice is violated by such regulation.

\section{$2 \quad$ Silencing and Legitimacy}

The suggestion that society itself has a propensity to stifle free expression is not new. The notion that the speech of some can silence the speech of others is familiar from the work of Rae Langton, Catherine MacKinnon, Owen Fiss, and others. ${ }^{22}$ Indeed, Alexander Brown explicitly proposes the thought as a way of challenging the legitimacy argument. ${ }^{23}$ If persons are silenced by others, then, following the legitimacy argument where it goes, the legitimacy of the state can be damaged by forms of social coercion and as such legitimacy might commend the state regulation of expression that silences in this way. This has real force against the conclusion that the value of legitimacy ought to constrain state regulation of hate speech. However, I believe that a stronger case can be

22 See, for example, Catherine MacKinnon, Feminism Unmodified: Discourses on Life and Law (Harvard University Press, 1987), Rae Langton, 'Speech Acts and Unspeakable Acts', Philosophy and Public Affairs 22 (1993), Owen Fiss, The Irony of Free Speech (Harvard University Press, 1996).

23 Alexander Brown, "Laws, Legitimacy, and Precaution," Constitutional Commentary Vol. 32 (2017), pp. 599-617, at p. 612. 
made for this conclusion than has thus far been offered. This is because, as it stands, the argument that hate speech can silence, and so undercut legitimacy itself, seems open to the persuasive retort that there is simply a lack of evidence for such an effect.

Briefly, there are three chief mechanisms offered in the literature as to how speech can silence. It can in some way damage or undercut the status of some persons as speakers who are worth listening to or understood, thus depriving their speech of efficacy, force or intended meaning; it can undermine the sense of self-worth of some persons such that they lack a self-conception of being a worthy speaker and valuable participant in the discursive domain; and it can crowd-out the speech by stifling the potential platforms others might have to speak themselves. At least with respect to the first two dynamics, there has been considerable skepticism concerning the availability of evidence to substantiate the claims that hate speech and pornography in fact 'silence' in the relevant ways. ${ }^{24}$

Existing silencing arguments can be supplemented, however, in a way that strengthens the case in favor of regulatory measures as a means to enhance democratic legitimacy. Many of the existing arguments concerning the putative societal silencing of expression relate to the way in which some persons (notably women and ethnic minorities) are deprived of meaningful opportunities to express, by way of their not being heard by others or not feeling able to speak. There is little existing analysis, however, of the ways in which societal phenomena have the propensity to stifle speech by way of disincentivizing the expression of certain things. ${ }^{25}$ What is more, emphasizing this dynamic of 'silencing' has the strategic advantage of highlighting social penalties that are relevantly similar in kind to the legal penalties that are already accepted by advocates of the legitimacy argument as freedom-restricting.

The state can restrict freedom either by making things more difficult or by making things more costly. ${ }^{26}$ When police physically remove a group of

24 See Dworkin - Women and Pornography; Weinstein - Hate Speech Bans; Weinstein Viewpoint Discrimination

25 Some notable exceptions include: Charles Lawrence, 'Crossburning and the Sound of Silence: Antisubordination Theory and the First Amendment,' Villanova Law Review 37 (1992), pp. 787-804, at p. 8oo; Mari Matsuda, 'Legal Storytelling: Public Response to Racist Speech: Considering the Victim's Story,' Michigan Law Review 87 (1989), pp. 2320-2381, at p. 2337; Caroline West, 'Words that Silence? Freedom of Expression and Racist Hate Speech', in Speech and Harm: Controversies Over Free Speech, I. Maitra and M. K. McGowan (eds.) (Oxford University Press, 2012) pp. 222-248, at pp. 233-234.

26 For a clear statement of this distinction see G. A. Cohen, "On The Currency of Egalitarian Justice," Ethics, 99 (1989), pp. 906-944, at p. 919. 
protesters they restrict the freedom to protest by rendering it more difficult. It delimits the opportunities available to express. When the state refrains from physical removal but imposes a massive fine for anyone present at a protest, it restricts the freedom to protest by making it more costly. It increases the burdens on expressing. At bottom, the legally imposed costs by the state are backed by the threat of imprisonment (which is, in fact, cost in the form of a downstream difficulty to move freely in society). The suggestion here is not that social penalties are as severe a consequence as that. However, the state also enforces law through financial sanction rather than physical incarceration. In this way laws prohibiting expression are backed by monetary costs that, one might suppose, are often efficacious at limiting the expression insofar as the costs serve as a meaningful disincentive to saying the things that the law disallows. I contend that civil society can inflict penalties of a relevantly similar severity such that they can stifle expression in much the same way.

Expression can invite a plethora of unpleasant consequences of varying degrees of seriousness. As is apparently increasingly common in an online era, one can receive death or rape threats, extreme vitriol, defamation, derision and mockery. The consequences can also include social ostracism, group exclusion, and loss of employment or ability to gain employment. Rather than defending in its own right the contention that these costs can be freedom-restricting, inasmuch as the argument is an internal examination of the implications of the legitimacy argument, it suffices here to compare the costs with some of those imposed by the state which are held to restrict freedom of expression. In many instances hate speech regulations are upheld by the imposition of a fine. In the UK this is often several hundred pounds. I hazard that it is plausible to view death and rape threats as, in some instances, more severe than such fines. Of course, not all such threats are made alike; their severity depends on their credibility and how widespread they are. But I suspect that the trauma and insecurity associated with even relatively non-credible threats can be at least as burdensome as being forced to pay a moderately heavy fine. Perhaps this will be readily conceded. One might observe, though, that threats are illegal, and persons are legally protected from them. So even if they can restrict freedom of expression, the state already prohibits such threats and so protects people accordingly. Although this is true, it probably underestimates the extent to which persons make online threats with relative impunity. What is more, this observation does nothing to undermine the claim that in principle these are costs that can restrict freedom of expression. Whilst vitriol, defamation, and even sometimes sufficiently widespread derision are arguably less burdensome as consequences to expression, they can still be very weighty 
indeed. More to the point, being a target of vitriolic speech, damage to reputation, and pervasive insulting expression can often be far worse than moderate monetary penalty.

Still, it might be argued that state penalties on free expression are importantly different in virtue of being intentionally imposed as freedom restrictions. It might be said that this is a prerequisite of their freedom-restricting character, and something which doesn't pertain to the aforementioned social costs. There are several reasons to question this. Firstly, even accepting that intentionality is important, it's quite plausible to think that the threats, vitriol, and employee firings that are prompted by speech of certain kinds are intentionally imposed as punishments and, more to the point, disincentives for speech. Secondly, present advocates of the silencing argument do not seem to rest their case on such a restricted view of what counts as a constraint on freedom. Thirdly, as I will explain, insofar as the 'chilling effect' on expression of legislation is a widely cited reason against the regulation of expression, so this implies a general acceptance that chilling reflects damage to freedom of expression, whether it is the state or society that is the culprit, and, indeed, whether or not the chilling is intentional. Those responses notwithstanding, there is some truth to this line of argument - that there is something special about the state's imposition of restrictions as compared with those created by wider society. It isn't, however, that only the former restricts freedom of expression, but that there may be something peculiarly problematic about the state being the body doing the restricting. This thought, in fact, is best expressed in terms of the third version of the legitimacy argument, the discussion of which I will postpone until section 4 .

Now, the argument I am forwarding is not strictly that legitimacy considerations necessarily counsel in favor of hate speech regulation but, rather, that the logic of the legitimacy argument grounds reasons in favor of regulation to protect speech silenced by the prospect of expressive costs. On this basis, the argument I have thus far made disrupts the legitimacy case against hate speech regulation only insofar as hate speech specifically embodies the kind of cost which I have argued can suppress expression. In view of this, a critic of hate speech regulation on legitimacy grounds might therefore cast doubt on whether the kinds of hate speech whose regulation is controversial in contemporary debate pose significant speech-disincentivizing costs. Although it might be conceded that threats and personal invective of the kind to which I have alluded are expression-stifling speech, the former are, as I have said, already widely recognized as regulable speech, and the latter forms of hate speech might be thought to fall under a 'fighting words' doctrine which defenders of the legitimacy argument may be happy to concede are 
regulable. ${ }^{27}$ In contrast, what tends to animate advocates of the legitimacy argument is an objection to the regulation of hate speech understood as contributions to 'public discourse.'

First and foremost, my argument is an internal critique of the legitimacy argument, rather than a defense of hate speech regulation per se. In that sense I am primarily concerned with establishing that legitimacy does not support a general constraint against regulation of 'viewpoint discriminatory' speech. The line of objection under consideration here does, however, suggest that this critique is less material to extant debates over hate speech regulation than my framing might suggest. Fully responding to this thought requires a more thoroughgoing examination of the harms of hate speech and the conceptualization of 'public discourse' than space permits. A couple of observations are in order, though. Firstly, in a first amendment context, which forms of hate speech fall into a category of 'fighting words,' which many may be happy to leave unprotected, is itself a contested question. For instance, whether targeted racial slurs constitute unprotected hate speech under that doctrine is unclear. ${ }^{28}$ I don't stake a claim in that debate save for suggesting that my argument - that such slurs have the potential to suppress expression - indicates that there are, in principle, legitimacy considerations that also potentially militate against their protection. ${ }^{29}$

Secondly, it does not seem implausible to suppose that at least some kinds of directed aspersion of the sort to which I allude above can both form part of 'public discourse' and stifle freedom expression by disincentivizing speech liable to invite it. Such a claim significantly hangs, of course, on what passes for 'public discourse.' It is worth noting that 'public discourse' is seldom conceptualized in narrowly political terms. ${ }^{30}$ Indeed, if 'public discourse' is construed narrowly, then any legitimacy argument against regulation specifically limited to 'public discourse' will be concomitantly narrow in scope. How to distinguish

27 First articulated in Chaplinsky v. New Hampshire, 315 U.S. 568 (1942).

28 See, for instance, Kent Greenawalt, Fighting Words (Princeton, 1996), at p. 51 who suggests that the Supreme Court has, since Chaplinsky, emphasized the significance of the prospect of immediate consequential violence as a determinant of what qualifies as 'fighting words.' See, for instance, Gooding v. Wilson 405 U.S 518 (1972) wherein the Court held that 'opprobrious' and 'abusive' speech is not necessarily 'fighting words' as defined in Chaplinsky, emphasizing that the latter relate to a tendency to cause a breach of the peace (and also making it clear that peace is not breached simply by the uttering of offensive words).

29 In other words, the case for their constituting unprotected speech is bolstered by such legitimacy considerations, over and above the potential such words have to inflict hurt and inflame hostilities.

30 Eric Barendt, Freedom of Speech (Oxford: Oxford University Press, 2007), p. 161; Heinze Hate Speech and Democratic Legitimacy, pp. 27-28. 
'public discourse' from other forms of speech is naturally contestable both in principle and application. ${ }^{31}$ Post defines public discourse as "encompassing the communicative processes necessary for the formation of public opinion, whether or not that opinion is directed towards specific government personnel, decisions, or policies." ${ }^{32}$ The mere fact that hateful invective is very often public in location - say, in the form of racist insults online - isn't enough to render it a part of public discourse. As Heinze comments, public discourse is more a matter of a type of speech - involving a message that "could plausibly be directed towards a sizeable audience" 33 - than a matter of the actual location of the speech, such as occurring in a public place, or being likely to reach a large audience. Even with this conception of public discourse in mind, however, it is plausible to think that hate speech in public discourse can constitute a disincentivizing cost to speech. Suppose a black person writes an opinion piece which predictably invites a swathe of online comments such as "this proves beyond doubt that blacks have low IQ," and "n*ggers don't know anything about politics." The context of such hateful speech conjoins the expression of viewpoints that are general in character, and hence plausibly a part of public discourse so understood, with a targeted vitriol such that it might constitute a cost and may form a meaningful disincentive to expression. Of course, there is a great deal more to be said on what forms of hate speech do qualify as public discourse in whatever sense one prefers to define it. The point of relevance is that it seems true that hate speech can be i. relevantly targeted towards an individual in a way that reflects a cost to that individual, ii. a consequence of expression (which, if foreseen, might discourage expression likely to invite it) and yet iii. framed in terms such that it can be reasonably interpreted as making a contribution, however noxious, to the shape of public culture. Where this is the case then the argument that legitimacy militates in principle in favor of regulation of speech has the requisite purchase. ${ }^{34}$

31 Post suggests that its boundaries are "inherently uncertain and subject to perennial reevaluation." Robert Post, Racist Speech, Democracy, and the First Amendment, William \& Mary Law Review 32 (1991), pp. 267-327, at p. 288; Heinze - Hate Speech and Democratic Legitimacy, p. 27. For some brief discussion concerning which instances of hate speech fall within or outside public discourse see Weinstein - Viewpoint Discrimination, p. $75^{8} \mathrm{fn} 172$. Post - Racist Speech, p. 288. Relatedly, Dworkin writes “[a] community's legislation and policy are determined more by its moral and cultural environment, the mix of its people's opinions, prejudices, tastes, and attitudes than by editorial columns of party political broadcasts or stump political speeches." Foreword viII.

33 Heinze - Hate Speech and Democratic Legitimacy, p. 27

34 Though I do not deny that the extent to which it is the case remains an open question. 
The above indicates that freedom of expression is eminently vulnerable to restriction by parts of civil society as well as the state. As such, if we consistently follow the legitimacy argument, the legitimacy damage inflicted by society is not an idle possibility but a real threat. Moreover, once we appreciate this, it seems that at least one prominent move in support of the legitimacy argument looks less plausible. As I have mentioned, a popular line of response to silencing arguments is to question how well such silencing has been empirically substantiated. In a forthright response of this form, Weinstein points to the paucity of evidence that persons are in fact silenced by hate speech. ${ }^{35}$ In contrast, he writes: "[i]t is indisputable that hate speech bans prevent people from expressing certain views in public discourse." 36 Weinstein's claim that it is 'indisputable' that hate speech bans prevent people from expressing certain views in public discourse is, in fact, ambiguous between two importantly different interpretations. On one hand, the claim could be a conceptual one - that, in contrast to societal factors, the coercive laws of the state clearly have the requisite features as freedom restrictions. On the other hand, the claim can be understood as an empirical one - that hate speech bans are characteristically efficacious in preventing the expression of hate speech. In neither instance, though, is it credibly indisputable that such bans restrict freedom of expression.

In the former instance, the notion that the laws of the state restrict the freedom of expression is hardly uncontested. It is contested, for instance, under the conception of freedom whereby only difficulties and not costs restrict freedom. ${ }^{37}$ On such a view, whilst state imprisonment restricts freedom, because it is no longer possible for the imprisoned to live in society, the mere legal threat of imprisonment for expressing oneself does not restrict the freedom of expression. ${ }^{38}$ So the idea that laws against expression restrict the freedom of expression is, I suggest, clearly disputable. If, alternatively, we interpret Weinstein's claim as an empirical one about the effectiveness of state hate speech laws in preventing the expression of prohibited speech, then it is

35 Weinstein - Viewpoint Discrimination, pp. 764-769; Hate Speech Bans, p. 758. It's worth noting that Weinstein's skepticism concerning the available evidence is directed specifically at evidence for the silencing effect of hate speech as public discourse.

36 Weinstein - Viewpoint Discrimination, p. 768, my emphasis.

37 Hillel Steiner, "Individual Liberty," Proceedings of the Aristotelian Society 75 (1974-75), pp. $33^{-5}$.

38 Though it may restrict their conjunctive freedom of expression and avoid imprisonment. See David Miller, “Constraints on Freedom," Ethics 94 (1983), pp. 66-86, at pp. 76-77. 
similarly in need of further support. As I indicated above, hate speech laws do their work in restricting freedom primarily by way of imposing costs on transgressing individuals. They do not make it impossible for citizens to express offending speech. Though the existence of the penalties may be uncontroversial, the effect of such penalties is not. If the claim is that the penalties prevent citizens from engaging in hate speech, then we may need to know the role that the penalties play in people's decisions whether to engage in the offending speech. Once we understand the argument in these terms, however, it's not clear without further evidence that state regulation prevents speech more, or more clearly, than the aforementioned social costs. Even if the comparison is between hate speech regulation and hate speech as a part of public discourse, rather than social costs more generally, it isn't clear, in advance of further studies to this effect, that state regulation has been more a more profound discouragement to speech.

Further to this, it is widely accepted, including by those who advocate the legitimacy argument, that speech can be 'chilled' even when it is not legally prohibited and, importantly, that such chilling can be legitimacy damaging. For instance, when discussing the Smith Act - a law during the Cold War which restricted advocacy for violent overthrowing of the US government Weinstein is clear that the law "had a detrimental effect on the legitimizing function of freedom of expression" by chilling other forms of "honest criticism" that didn't constitute advocacy of the prohibited kind. ${ }^{39}$ Technically, the difference between speech that is chilled by state regulation as compared with speech that is 'restricted' is that the latter in fact breaches the law, whereas, say, the former is merely perceived to fall (or perceived to run the risk of falling) foul of the law. ${ }^{40}$ Now, that difference may be important in certain respects, one of which is the focus of section 4 , but if our question is the empirical one of which factors 'prevent' expression (and, in that sense, stop expression which would otherwise have obtained), then it's not clear that this difference, in advance of some further evidence, shows us that the 'restricting' effect of state regulation does more to prevent expression than the state chilling of expression. In the very same way, we need evidence for the greater preventing effect of state 'restricting' vs. societal chilling. It should be clear, therefore, that one of the important merits of the claim that societal factors can damage freedom of expression by way of disincentivizing speech of certain kinds, and in that

39 Weinstein - Viewpoint Discrimination, p. 733. He also emphasizes that "we need to consider not just the effect on [actually penalised] speakers but also the "chilling effect" ... on would-be speakers." Ibid., p. 751 .

40 Or, running the risk of rendering oneself liable to cost as a result of being prosecuted. 
way corrode legitimacy by frustrating certain persons' democratic say, is that it depends on an appeal to the very same dynamic of freedom restriction that the advocates of the legitimacy argument readily admit.

The argument thus far has maintained that freedom of expression can be restricted by both the state and by societal factors. In view of this, I have argued that inasmuch as restrictions on expression with a societal source can be similarly legitimacy damaging, the value of legitimacy might, in principle, ground regulatory measures offering protection for expression from social restriction. Some of Dworkin's remarks in defense of the legitimacy argument suggest a line of response to this argument - one that, in fact, reflects a quite distinct legitimacy case against state regulation and embodies the third version of the legitimacy argument, foreshadowed above. Dworkin asserts that citizens have a 'right of ethical independence,' which entails that the state must not coercively enforce a particular ethical conviction, including, for instance, the conviction that each person is owed equal concern and respect. ${ }^{41}$ On Dworkin's view, the state regulation of hate speech is tantamount to the enforcement of just such an ethical conviction because it suppresses a form of citizen dissent by specifically targeting a viewpoint on the grounds of its falsity or offensiveness, and thereby imposes a view concerning the moral viewpoint that citizens ought to hold. To do so, Dworkin suggests, is to fail to respect citizens' dignity as ethically independent.

Whatever the force of this argument, it should be clear that it is importantly distinct from the legitimacy argument characterized in the above. In this third, Dworkinian version, the damage to legitimacy is not wrought first and foremost in virtue of some persons lacking an equal voice in the democratic discursive forum, but because the very act of depriving persons of a voice is a violation of legitimacy constraints that pertain to persons' right of ethical independence. ${ }^{42}$ Violating such a right, for Dworkin, involves a forfeiture of the moral title to exercise coercive rule. He writes that, "[t]he majority has no right to impose its will on someone who is forbidden to raise a voice in protest

\footnotetext{
41 Dworkin - Reply, p. 342.

42 In fact, Weinstein also at times seems to embrace an argument of this form when he suggests that "there comes a point at which a speech restriction, like selective disenfranchisement, can so profoundly disrespect both the interests and equal moral worth of some individuals." Weinstein, Reply, p. 727 .
} 
or argument or objection before the decision is taken." ${ }^{33}$ As he puts it in the context of the state enforcing a view about the equal dignity of fellow citizens, "it does not lie within the powers of just government to try to identify and impose that truth." ${ }^{44}$ This indicates that it is a specific kind of wrongdoing - an overstepping of the bounds of authority, limited by citizens' rights - on which the illegitimacy of the viewpoint non-neutral regulation of speech is grounded. It is for this reason that Dworkin seems to embrace the illegitimacy of hate speech regulation itself as well as the legitimacy effect of upstream hate speech laws on downstream non-discrimination laws. Hate speech regulation damages legitimacy not only in the form of its consequences for persons' equal participation in democratic contestation, but as a violation itself of a particular ethical constraint related to treating persons with equal concern and respect. By making the exercise of state coercive power specifically conditional on refraining from violating the ethical independence of citizens, this version of the legitimacy argument appears to side-step the response that civil society itself threatens legitimacy. ${ }^{45}$ However, this version of the legitimacy argument fails as a general objection to the regulation of hate speech, or indeed to the regulation of speech that has the propensity to silence others.

\section{5}

Viewpoint Discrimination and a Right to Ethical Independence

However important freedom of expression is (and it is no doubt very important), few accept the view that state curtailment of expression is always impermissible. Fraud, conspiracy to commit terrorism, and libeling of private citizens are all types of expression that are widely, and appropriately, considered legitimately subject to state restriction. A right to ethical independence is therefore implausibly strong if it is supposed to guard against state incursion on any and every form of expression that a citizen might want to engage in. Critics of hate speech regulation, including Dworkin, avoid this concern by arguing that it is specifically viewpoint non-neutral regulation that is legitimacy damaging. Hate speech regulation is objectionable at the bar of legitimacy because it depends on a justification which condemns (as false, immoral, or offensive) the viewpoint from which the regulated speech issues and, in that way, discriminates against that viewpoint. Because the regulations on things

\footnotetext{
43 Dworkin - Foreword viI.

44 Dworkin - Reply, p. 343.

45 Or, more precisely, it side-steps this as an internal implication of the legitimacy argument as a reason against speech regulation.
} 
like fraud, conspiracy to commit terrorism, and libel, as well as those on the time, place, and manner of expression, are not (necessarily) viewpoint discriminatory in that way, they don't constitute the affront to legitimacy that viewpoint discriminatory regulation does. The right to ethical independence, and its appeal as a basis for repudiating hate speech regulation as legitimacy damaging, therefore, crucially depends on characterizing such regulation as objectionably viewpoint discriminatory.

The objection to this move, though, is to cast doubt on whether the regulation of things like hate speech really is viewpoint discriminatory in the relevant sense, given that the intended regulation may seek to regulate the manner, rather than the substance of what is expressed. In that respect is it important that hate speech law targets the vituperative ways in which a viewpoint is expressed and seeks, as Waldron puts it, to "try to define a legitimate mode of roughly equivalent expression." 46 Though this move is an important one, it is apparently vulnerable to a compelling riposte, namely that the distinction between the substance of a viewpoint and the manner of its expression is, in fact, an unsustainable one. To make this point, Robert Post mentions the poet Shelley's reference to the "vanity of translation" and the idea that the linguistic vehicle of expression is intimately bound with the ideas that are conveyed. Post explains, therefore, that "to the extent that language is conceived as thick and material, as resisting translation, hate-speech regulations must be understood as suppressing particular ideas from being communicated." ${ }^{47}$ Heinze makes the same point when he argues that we "cannot coherently divide acts of human expression into two parts - on the one hand, the substance of a message, conveying its viewpoint, and, on the other hand, that message's particular form of words, which might somehow be regulated without affecting the viewpoint." ${ }^{\text {48 }}$

I think that the critics of hate speech regulation are in one sense quite right in insisting that the substance and manner of expression are intimately tied in this way, and that the way that something is expressed is material to the meaning of the expression. There are, however, three reasons why this doesn't support the idea that regulating the manner of expression is viewpoint non-neutral in an objectionable way. Firstly, to appeal to the connection between substance and manner in order to claim that manner-targeting regulation remains viewpoint discriminatory suggests too strong a conclusion. Though differences in the linguistic mode of expression may indeed reflect differences in its meaning, this

46 Waldron - Hate Speech and Political Legitimacy, p. 334.

47 Robert Post - Legitimacy and Hate Speech, p. 656.

48 Eric Heinze - Taking Legitimacy Seriously, p. 632. 
point also straightforwardly generalizes to the context of expression. After all, the meaning of words depends on the context in which they are uttered, and, indeed, the meaning of actions is dependent on context in that same way. The problem with this implication is that it now looks like the so-called time, place, and manner restrictions, which are more widely agreed to affirm a permissible basis for speech regulation, are similarly problematic on the grounds of viewpoint discrimination, thus construed. If we accept, as we should, that the words that are used affect the meaning of the expression, then we should also accept that where and when an expression takes place bear a similar relation to its meaning. Consider, for example, the famous instance of the lone protester in Tiananmen Square blocking a line of tanks from progressing forward. The meaning of that act of expression is inextricably bound to the time, place, and manner of its occurrence. The visceral immediacy of the juxtaposition between the lone figure and the arsenal of weapons is simply lost if expressed at a different time and place, or in a different way. ${ }^{49}$ This suggests the following dilemma: either we accept the idea that all regulation of the vehicle of expression delimits the substance of what can be expressed in a way that is objectionably viewpoint discriminatory, in which case we are saddled with the troubling conclusion that time, place, and manner restrictions are also legitimacy damaging, or we accept that there is a basis for distinguishing objectionable from unobjectionable regulation of the vehicle of expression even if in every case the substantive expression of a viewpoint is to some degree restricted. Yet if we take this latter horn of the dilemma, there is nothing to rule out the possibility that manner-targeted hate speech regulation falls on the unobjectionable side.

Secondly, there is a danger of simply placing too much significance on the inextricability of manner and substance. Though regulating the manner of expression does not leave space for people to express the exactly equivalent viewpoint, it might still offer a space for roughly equivalent expression. For instance, if I use a different set of words to write an article in which I understand myself to be arguing the same thing, it might mean something marginally different, but, depending on how integral the particular wording is, and how proximate the alternative vehicle of expression, the differently worded article might still mean much the same thing. This exposes how a pedantic preoccupation with marginal differences in meaning can distract us from what it was that made viewpoint discrimination seem objectionable in the first place. It looked objectionable because it involves depriving people of the

49 Strictly, my argument doesn't depend on this being true; it depends on it being no less plausible to suppose that it is true in respect of the context of expression as it is in respect of the language used for expression. 
possibility of voicing their perspective - their weltanschauung - to the wider world. However, although we clearly need words to be able to disclose ourselves to others, and to be deprived of certain key conceptual tools to articulate one's view would no doubt be a profound hindrance, taking certain limited ways of expressing a view off the table need not always significantly muzzle the expression of a world view, even if one is forced to be more imaginative about the ways to communicate it.

Thirdly, if our question is whether the justification for regulation is viewpoint discriminatory or not, rather than whether regulation has the effect of hindering the expression of certain points of view, I suggest that the manner vs. substance distinction is less significant than some existing work might lead us to suppose. As Waldron rightly emphasizes, hate speech regulation is only "sort of content-based, but mostly ... get[s] at content only by virtue of its intended effect on the community, rather than on the sole basis of the propositions expressed."50 In other words, what is targeted by hate speech regulation are certain specific intended effects. In that sense, the forms of hate speech regulation many defend are, at bottom, not justified on the basis of the offensiveness, falsity, or immorality of the substance of speech nor even on the manner of speech but on the intended effects to which they give rise. ${ }^{51}$ This is significant because it seems to be a supposition of this Dworkinian version of the legitimacy argument that the regulation of hate speech embodies a judgment about the lesser worth of the regulated viewpoint. However, if the justification for regulation is not the objectionable character of the viewpoint itself but the effects of its expression, then the affront to the dignity of those whose speech is restricted is far less clear.

The claim that viewpoint discrimination is both present and objectionable in instances of hate speech regulation is a critical one for the legitimacy argument of both forms, but perhaps especially important for the Dworkinian one, given that it places such emphasis on the wrongful, rights-violating character of state discrimination specifically. In response to this last argument regarding regulation that targets the effects of speech and not the content itself, it might plausibly be maintained that this move simply uses 'effects on others' as a conduit to smuggle in an opposition to the character of the viewpoint itself. That is

50 Waldron -Conditions of Legitimacy, p. 701, my emphasis.

51 Things are slightly more complicated when it is argued that the wrongfulness of hate speech justifies its regulation, rather than merely its harmful effects on others. Here it clearly is the case that the immorality of the speech is the claimed basis for its regulation. It is important, though, that the wrongfulness in question is understood as a wronging of others. If it is precisely the expression of the viewpoint (though a particular manner) that wrongs others, I think that it is appropriate to say that this basis for regulation is viewpoint discriminatory. 
to say, because the relevant effects on others obtain only because others judge the viewpoint false or offensive, regulation justified by these effects is extensionally equivalent to regulation justified directly by the falsity or offensiveness of the viewpoint itself. This is a powerful response but nevertheless still an unsuccessful one. Firstly, if one's claimed justification for regulation is the effects on others whereas in fact it is merely an insincere veneer that simply re-frames an objection to the viewpoint itself, then I agree that the regulation may remain viewpoint discriminatory in the relevant way. But that is because the notion of effects isn't doing any meaningful work in the argument and the viewpoint itself remains the real target. However, even if much existing regulation in fact embodies such insincerity, there is nothing to suggest that it must necessarily do so. Secondly, the objection may be trading on the notion that some effects on others, such as their judgment that speech is false or offensive, are simply inappropriate grounds for speech regulation. One might argue, for instance, that being offended as a consequence of the beliefs which one holds is simply something for which individuals ought to accept liability. ${ }^{52}$ That may well be true, but it doesn't show that this is a matter of targeting the viewpoint itself, rather than its effects. ${ }^{53}$

Of course, it might still be argued that because the transmission of the would-be negative effects of the regulated speech is mediated via the beliefs which others have about the value of the viewpoint, to regulate the speech because of those effects itself involves taking a view about the value of the viewpoint. Weinstein comes close to this view when he argues that even if regulation of speech is justified in terms of the "'the harmful consequences" of the speech ... if the harm in question is claimed to result from the expression of a particular point of view [then] a law suppressing that point of view nonetheless is still based on that viewpoint." ${ }^{54}$ Weinstein's claim that laws suppressing a point of view in virtue of the putative consequences of its expression are still "based on" that viewpoint is, in fact, ambiguous as to what being 'based on' means. It is true that the laws appeal to the viewpoint as a premise in the argument for why the speech ought to be regulated, but they need not be 'based on' the viewpoint in the sense of prejudging the value of the viewpoint itself. If the state restricts speech that spreads a putatively inflammatory ideology

$5^{2} \quad$ For a relevant discussion see Peter Jones, "Bearing the Consequences of Belief," Journal of Political Philosophy 2 (1994), pp. 24-43.

53 It might be important here to distinguish between the fact that people are offended by an expression and a judgment that the expression is offensive where the latter might be understood to involve a judgment about the moral character of the expression that the former does not.

54 Weinstein - Viewpoint Discrimination, p. 747 fn 125, his emphasis. 
encouraging terrorist attacks on fellow citizens precisely on the basis that the spread of a belief causes harm against which it has a responsibility to protect, it targets the result of such belief in a way that doesn't necessarily evaluate the character of the viewpoint in a way that goes beyond this. When this is the justification for regulation, it is hard to see the sense in which it violates a right to ethical independence, understood in the terms put forward by Dworkin. ${ }^{5}$

The most promising response to these challenges to Dworkin maintains that there are some forms of regulation of speech whereby the claimed harm isn't merely contingently related to the beliefs expressed by the regulated speech but is in some sense constituted by those beliefs. In the terrorist case, there is a contingent gap between people believing the viewpoint (embracing terrorist ideology) whose expression is regulated and the harms (terrorist attacks) said to be consequent on the expression that are the target of regulation. It might be argued that this isn't true of other cases. Indeed, troublingly for advocates of hate speech regulation, this isn't true for several of the prominent justifications for the regulation of hate speech. For instance, consider Waldron's view that hate speech is objectionable, and regulable, because it undercuts persons' assurance of dignity and status in civil society. ${ }^{56}$ Given that one's social status is constituted by the beliefs of others and how one is regarded by them, regulating speech in the service of protecting persons from damage to their dignitary status inextricably entails a judgment about the inappropriateness of certain beliefs. Beliefs about others' inferiority are precisely part of the consequences that the regulation seeks to pre-empt. Regulation for these reasons thereby seems to involve viewpoint discrimination in the sense that it targets the value of a viewpoint. To briefly draw a parallel, if we regulate the expression of a viewpoint on the grounds that it has the consequences of leading persons to hold false beliefs,' it wouldn't pass muster to claim that the regulation was justified on the grounds of the consequences of the viewpoint expression as opposed to on the basis of its falsity.

Though I think that this is compelling, I don't think that it is decisive as a general legitimacy-based case against hate speech regulation. Rather, I think that it shows is that if the grounds for regulation are specifically that it would be bad in itself if a given viewpoint came to be believed, then the regulation prejudges the value in a discriminatory way. As such, it illuminates the sense in which when belief in the regulated viewpoint is very closely related to the consequences on which the regulation is justified, distinguishing the two in order to avoid complicity in viewpoint discrimination is a delicate and difficult task.

55 Though there may be other good arguments against such state regulation, of course.

56 Waldron - Harm in Hate Speech. 
Rather than conceiving of viewpoint discrimination in terms of the targeting of speech on grounds of its falsity or offensiveness, we could understand it in terms of indirect discrimination relating to the unequal impact that speech regulation can have on the expression of different viewpoints. Thus understood, legitimacy damage is inflicted when certain persons are deprived, through state regulation, of an equal opportunity to express their viewpoint, even if the viewpoint isn't itself specifically targeted. If this argument is to be something more than simply a restatement of the legitimacy argument considered in the first part of the paper, then we need to say something more about the significance of the state imposing measures that makes it objectionably indirectly viewpoint discriminatory.

The two clearest ways in which one might try and make that case are as follows. Firstly, that the state regulation of hate speech expresses something about the unequal status of those with viewpoints whose expression is restricted. Secondly, that the burdens of hate speech regulation fall unequally across different persons in a way that is unfair.

The first line seems to cohere with some of Dworkin's remarks concerning the legitimacy affront involved in viewpoint discriminatory regulation. He emphasizes the sense in which enjoying freedom of expression confirms individuals' public dignity, and argues that state regulation of freedom of expression is inconsistent with "respect [for] each individual's status as a free and equal member of the community."57 Speech regulation may indeed sometimes express something about the unequal status of certain citizens in a way that is objectionable and potentially legitimacy damaging. However, there are a number of reasons why this doesn't support a legitimacy case against speech regulation in general. There is a wealth of work on the question of the expressive character of state action, but I think that some of the clearest cases of expressing inferiority of citizens involves action which deprives citizens of the intersubjective prerequisites for being recognized as an equal in civil society. One of those prerequisites is indeed, ordinarily, having a voice to express oneself (at least when others also do). However, in this context it is important that, as I have mentioned, commonly defended forms of hate speech regulation only target certain ways of expressing oneself as opposed to offering a more wholesale regulation of a viewpoint. Such regulation manifestly does not constitute the wholesale disenfranchisement of certain citizens (which very plausibly expresses inferiority) but only involves a set of limited restrictions,

Dworkin - Foreword VII. 
often expressly designed to minimize the impact on the speech opportunities of those who might be restricted by them. What is more, and relatedly, it is plausible to think that the expressive character of speech regulation is subject to interpretation, given the context and the significance that is placed on the forms of behavior regulated by the state. So, how far state regulation is reasonably interpreted as expressing the lower status of certain citizens will vary with context. It will depend, among other things, on the meaning that the citizenry in general give to being able to express whatever one wants in whatever way one wants. Furthermore, to echo some of the arguments offered in the earlier parts of the paper, both the equal status of citizens and, more especially, their voice can be threatened by phenomena other than the state. Given that the state can be accountable for both what it positively institutes and what it fails to counteract, the state could have a responsibility to take measures, including speech regulation, which offset the damage to citizens' equal status as expressive agents. In reply, perhaps it could be said that this argument willfully ignores an important dimension of this version of the legitimacy argument, namely that there is something peculiarly objectionable about the state acting to regulate speech, given that it has a special responsibility to refrain from expressing the inferiority of certain citizens. However, this misses the force of the argument. The idea is that because the state has a responsibility to protect citizens from certain challenges to their equal status or certain assaults on their freedom of expression, regulatory intervention to that end could be what is required to express the equal status of citizens.

So, to the second line of argument - that the burdens of speech regulation fall unequally across different persons in a way that is unfair. Hate speech regulation, for instance, would impose a burden of restriction on those who want to express racial intolerance, and not on those who want to express racial tolerance. Again, I doubt whether this is a successful rescue of this form of the legitimacy argument. State action falls unequally on different citizens in all sorts of ways. Some of those involve unfairness, but mere inequality in state burdens isn't enough to show that the state action is illegitimate, even if it's unfair. If perfect fairness were a prerequisite for legitimacy, then inequality in the burdens of speech regulation is hardly the place to start. What the argument does point towards is that inequalities of burden of the sort that hate speech regulation entails may indeed stand in need of justification.

It might be argued that there is something about expressive burdens falling unequally which damages legitimacy. However, this claim needs explaining, and the most compelling ways of explaining it are either that limiting persons' equal opportunity to speak expresses something about their unequal democratic status - an argument to which I have already responded - or that any 
speech regulation unfairly deprives persons of their capacity to participate in the democratic process. If it is understood in this latter sense, however, then the arguments of the first part of the paper have shown that persons can be meaningfully deprived of that capacity by sources other than the state, and so legitimacy may in principle call for the regulation of expression, rather than prohibit it in general.

\section{7}

\section{Conclusion}

Though I have challenged the legitimacy arguments against the regulation of speech, I believe that it is amongst the more powerful of the arguments trained against such regulation, and, suitably construed, offers important insight into when and why regulation might be impermissible. One of the important features of the legitimacy arguments is its capacity to highlight the legitimacy affront involved in a state pre-empting the democratic contestation, plausibly required for its own legitimacy, by adopting coercive measures that intentionally aim to manipulate the conclusions that the citizen body draw concerning how the state should be constituted. This, I take it, was a part of what drove Bernard Williams to insist that legitimacy depends on the satisfaction of the Critical Theory Principle: the claim that an "acceptance of a justification does not count if the acceptance is itself produced by the coercive power which is supposedly being justified." ${ }^{58}$ Bearing this in mind, I think that there are three things that the legitimacy arguments against speech regulation show are problematic. These are a significant deprivation of citizens' resources to engage in appropriately autonomous contestation; the creation of meaningful inequalities in citizens' opportunities to engage in democratic contestation; and the intentional elimination of the presence of a particular viewpoint on the basis that there is something inappropriate or objectionable about the viewpoint itself. What is not true, however, despite what several advocates of legitimacy arguments have appeared to maintain, is that legitimacy places a strict constraint on viewpoint non-neutral regulation of expression.

\section{Acknowledgements}

For valuable comments I would like to thank Elizabeth Frazer, Cécile Laborde and James Weinstein, as well as an anonymous reviewer for the journal. I'm

$5^{8}$ Bernard Williams, "Realism and Moralism in Political Theory," in his In the Beginning was the Deed: Realism and Moralism in Political Argument (Princeton University Press, 2005). 
also grateful to participants at a workshop held by the Centre for the Study of Social Justice, University of Oxford and a reading group at New College, Oxford

\section{Biographical Note}

I am a Departmental Lecturer at the University of Oxford. My main research interests relate to equality, agency and freedom of expression. 